\title{
APROVECHAMIENTO DE LOS RESIDUOS SÓLIDOS ORGÁNICOS DE LAS FRUTAS MEDIANTE DIGESTIÓN ANAEROBIA
}

\section{USE OF ORGANIC SOLID WASTE OF FRUITS THROUGH ANAEROBIC DIGESTION}

\author{
Vera-Loor José ${ }^{1 *}$; Anchundia-Vélez Gema ${ }^{2}$; Sccipa-Mendoza María ${ }^{3}$ \\ ${ }^{1}$ Universidad Técnica de Manabí, UTM. Portoviejo, Ecuador. \\ ${ }^{2}$ Universidad Técnica de Manabí, UTM. Portoviejo, Ecuador. \\ ${ }^{3}$ Universidad Técnica de Manabí, UTM. Portoviejo, Ecuador.
}

*Correo: josveraloor@gmail.com

\begin{abstract}
Resumen
Debido al gran volumen de residuos de frutas que se generan diariamente en diversas operaciones relacionadas con el procesamiento de frutas, verduras, entre otros, y las actividades económicas de origen agroindustrial, se plantea que es posible realizar la digestión anaeróbica de estos residuos biodegradables. Es por esta razón que la investigación tiene como finalidad discutir las bases teóricas que fundamentan el aprovechamiento de los residuos sólidos orgánicos de las frutas mediante procesos de digestión anaerobia. En la actualidad los residuos sólidos orgánicos (fracción húmeda) de la industria no tienen un objetivo específico para su uso, la mayoría de ellos son enviados al basurero. Dada la necesidad de aprovechar los residuos de cáscaras de frutas se requieren biorreactores debidamente diseñados y construidos. El uso de combinaciones de residuos sólidos orgánicos de las frutas en procesos de digestión anaeróbica puede potenciar la producción o rendimiento de metano y a su vez generar mayor productividad y factibilidad desde la perspectiva económica. En este sentido, la piña y naranja pueden ser evaluadas para determinar la relación óptima para obtener mayores rendimientos de producción energética (metano).
\end{abstract}

Palabras clave: bioconversión, metano, subproductos, frutas, digestión anaerobia.

\begin{abstract}
Due to the large volume of fruit residues that are generated daily in various operations related to the processing of fruits, vegetables, among others, and the economic activities of agro-industrial origin, it is suggested that it is possible to perform anaerobic digestion of these biodegradable residues. It is for this reason that the research aims to discuss the theoretical bases that underlie the use of organic solid waste from fruits through anaerobic digestion processes. Currently, organic solid waste (wet fraction) from industry does not have a specific objective for its use, most of it is sent to the landfill. Given the need to take advantage of fruit peel residues, properly designed and constructed bioreactors are required. The use of combinations of organic solid residues from fruits in anaerobic digestion processes can enhance methane production or yield and, in turn, generate greater productivity and feasibility from an economic perspective. In this sense, pineapple and orange can be evaluated to determine the optimal relationship to obtain higher energy production yields (methane).
\end{abstract}

Keywords: bioconversion, methane, by-products, fruits, anaerobic digestion.

Información del manuscrito:

Fecha de recepción: 04 de mayo de 2017

Fecha de aceptación: 26 de junio de 2017

Fecha de publicación: 10 de julio de 2017 


\section{Introducción}

Debido al gran volumen de residuos de frutas que se generan diariamente en diversas operaciones relacionadas con el procesamiento de frutas, verduras, entre otros, y las actividades económicas de origen agroindustrial, se plantea que es posible realizar la digestión anaeróbica de estos residuos biodegradables, para obtener una producción considerable de mezcla gaseosa combustible con contenido de metano superior al $50 \%$ en volumen (Demirbas \& Ozturk, 2005; Rizk et al., 2007).

En lo que se refiere al cambio climático y la contaminación por residuos sólidos orgánicos en el Ecuador, la situación actual obliga a buscar alternativas para la optimización de los residuos, de tal manera que se evite la producción de gases contaminantes que aumenten el efecto invernadero, se reduzca el volumen de basura en los rellenos sanitarios y se disminuya la contaminación de las fuentes hídricas.

Una de las alternativas para tratar los residuos orgánicos, es el uso de un biorreactor anaeróbico, que contribuye con la digestión bacteriana en ausencia de oxígeno con el fin de obtener productos biodegradables y no contaminantes como lo son el gas metano (GarciaPeña et al., 2011; Zhao et al., 2016), dándole un valor agregado a los residuos de frutas de alto consumo en el Ecuador, como la cáscara de naranja y piña que comúnmente tienen como fin el relleno sanitario.

Cada día la industria ecuatoriana va tomando conciencia de la necesidad de reutilizar los recursos y materias secundarias provenientes de sus procesos con el fin de optimizar la producción. En esta búsqueda de procesos que generan ahorros significativos de insumos y otorgan valor agregado a los residuos; nace la idea de aprovechar los residuos de las plantas de procesamiento de productos agroindustriales. Los residuos más abundantes en el sector agro-industrial ecuatoriano son de banano, café, cacao, flores, palmito, maíz, cascarilla de arroz, papas y frutas (Gavilanes-Terán et al., 2015). La presente investigación tiene como finalidad discutir las bases teóricas que fundamentan el aprovechamiento de los residuos sólidos orgánicos de las frutas 
mediante procesos de digestión anaerobia.

\section{Residuos sólidos orgánicos}

Los residuos orgánicos representan una inmensa pérdida de recursos y de energía, de manera que pueden ser considerados como un indicador de la eficiencia en el uso de los materiales en una sociedad (Gavilanes et al., 2015).

En la actualidad los residuos sólidos orgánicos (fracción húmeda) de la industria no tienen un objetivo específico para su uso, la mayoría de ellos son enviados al basurero. En la Tabla 1 se muestran los porcentajes de los residuos sólidos en las zonas urbanas del Ecuador.

Tabla 1.

Naturaleza y composición de los residuos sólidos urbanos en el Ecuador

\begin{tabular}{ccc}
\hline Naturaleza & $\%$ & $\begin{array}{c}\text { Producción } \\
\text { (ton/día) }\end{array}$ \\
\hline Materia orgánica & 71, & 5298 \\
Papel y cartón & 9,6 & 709 \\
Plástico & 4,5 & 336 \\
Vidrio & 3,7 & 274 \\
Metales & 0,7 & 53 \\
Total & 100 & 6669
\end{tabular}

Fuente: Gavilanes et al., 2015.

La acumulación de estos residuos y un inadecuado manejo, causa la proliferación de vectores y enfermedades gastrointestinales y respiratorias, contaminación de agua, atmósfera y suelos, así como también problemas de conservación de flora y fauna (Zhao et al., 2016).

\subsection{Residuos de origen vegetal}

Debido al tipo de actividad en la que esté involucrada la materia orgánica se pueden considerar cuatro puntos de generación de los restos vegetales: residuos forestales, residuos agropecuarios, residuos industriales y residuos urbanos. Generalmente, los residuos vegetales están formados por restos de plantaciones (ramas, corteza, raíces), restos de cosechas (tallos y hojas, cáscaras, maleza, pastura), restos industriales (pulpa y cáscara de frutas y vegetales, así como también grasas y aceites vegetales) y residuos urbanos (desechos domésticos orgánicos). Los restos vegetales han pasado a constituirse en el principal residuo procedente de la actividad agraria e industrial (alimentaria) suponiendo un peligro para la propia actividad que los genera tanto en su fase productiva como de transformación. Constituyen uno de los principales vectores de transmisión de plagas y enfermedades a la vez que son una 
fuente importante de materia orgánica (Cioabla et al., 2012). La tabla 2 muestra el volumen de biogás producido por cada tonelada de residuo vegetal.

\section{Tabla 2.}

Producción de biogás a partir de residuos vegetales

\begin{tabular}{|c|c|c|}
\hline Residuo & Cantidad & $\begin{array}{l}\text { Volumen } \\
\text { de biogás }\end{array}$ \\
\hline $\begin{array}{c}\text { Cereales } \\
\text { (paja) }\end{array}$ & 3,3 & 367 \\
\hline $\begin{array}{c}\text { Tubérculos } \\
\text { (hojas) }\end{array}$ & 10 & 606 \\
\hline $\begin{array}{l}\text { Leguminoso } \\
\text { s (paja) }\end{array}$ & 3,2 & 518 \\
\hline $\begin{array}{c}\text { Hortalizas } \\
\text { (hojas) }\end{array}$ & 5,5 & 603 \\
\hline $\begin{array}{l}\text { Frutas } \\
\text { (cáscaras) }\end{array}$ & 6,4 & 514 \\
\hline 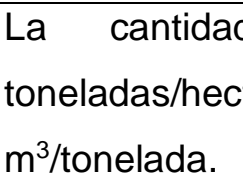 & $\begin{array}{l}\text { está } \\
\text { ea y el }\end{array}$ & $\begin{array}{ll}\text { nedida } & \text { en } \\
\text { volumen } & \text { en }\end{array}$ \\
\hline
\end{tabular}

Fuente: Gavilanes et al., 2015.

\section{Subproductos}

Un subproducto es un producto secundario, bien conocido, generalmente útil, comercializable y por lo tanto con valor agregado, que resulta de un proceso industrial. El término "residuos", se aplica a aquellos que pueden tener o no un valor comercial, porque son poco comunes o porque se generan en bajas cantidades, sin embargo, algunos de sus constituyentes aún en baja proporción, le pueden conferir algún interés para su utilización. Desde este punto de vista, los términos "subproducto" y "residuo" podrían utilizarse como sinónimos, no así el término "desecho", que está referido a aquellos materiales que no tienen algún valor comercial, ni poseen atributos de interés para ser utilizados en algún proceso, por lo que se consideran como basura y se les debe dar una disposición final. Al buscar una oportunidad de aprovechamiento de los residuos, se hace necesaria su caracterización para conocer su composición, la calidad de sus componentes y la cantidad que se genera, con esto se pueden definir las tecnologías más apropiadas para su aprovechamiento y posterior tratamiento. Respecto a esto último, es de esperar que después del aprovechamiento de un residuo se genere un siguiente residuo más agotado que podría tener otra aplicación, o bien, convertirse en un desecho. En la búsqueda de oportunidades de aprovechamiento de residuos este aspecto deberá ser considerado, con un enfoque de responsabilidad ambiental (Instituto de Ingeniería, 2012; Saval, 2012). 


\subsection{Naranja}

La naranja es la fruta cítrica del naranjo (Citrus aurantium), con dos subespecies principales: el naranjo dulce (subespecie Sinensis) y agrio (subespecie Amara). Se la denomina cítrica por su contenido en ácido cítrico, que le confiere el sabor amargo. La naranja es un fruto hesperidio (pulpa carnosa entre el endocarpio y las semillas en forma de gajos llenos de zumo), de corteza lisa y más o menos endurecida con vesículas oleosas. Tiene sabor dulce o ligeramente agrio, dependiendo de la variedad (Xu, 2013).

La naranja es la fruta que más se produce en el mundo y la de mayor consumo per cápita. Proviene del sureste de Asia y pertenece al género de Citrus de la familia de las Rutáceas (Rutaceace). Entre los diferentes tipos de naranja, las variedades de naranja dulce (Citrus sinensis) son las más importantes a nivel comercial. Según datos de la FAO, el Ecuador ocupa el puesto 24 en el ranking mundial de productividad de naranja con 23820 $\mathrm{Ha}$ de superficie de cosecha (Xu et al., 2013).

Los frutos del naranjo, llamados hesperidios, son bayas modificadas que presentan una curva de crecimiento del tipo sigmoidea simple. La fecha de maduración y cosecha de los frutos se extiende por un período prolongado, entre julio y febrero, y su duración dependerá de factores climáticos, de la variedad de naranjo usada y de las labores que se efectúen en el huerto.

La naranja tiene una forma esférica de un diámetro que oscila entre 6 a $10 \mathrm{~cm}$, es más pequeña y dulce que el pomelo o toronja y más grande, aunque menos perfumada, que la mandarina. Existen numerosas variedades de naranjas en la que su color y sabor difiere de acuerdo a la variedad (Xu et al., 2013).

\subsubsection{Propiedades}

Es un cítrico con propiedades refrescantes y un importante valor nutricional, contiene fibra y minerales necesarios para una dieta balanceada como son potasio (K), calcio $(\mathrm{Ca})$, magnesio $(\mathrm{Mg})$, además de un alto contenido de vitamina $\mathrm{C} y$ ácido fólico. Igualmente contiene cantidades apreciables de flavonoides (sustancias biológicas naturales con potencial para reducir el riesgo de cáncer y enfermedades cardiovasculares) y $\beta$-caroteno, el cual le da su color anaranjado y 
posee propiedades antioxidantes, que se transforma en vitamina $A$ conforme el cuerpo lo necesita, y es esencial para la visión, el buen estado de piel, cabello, huesos, mucosas y el buen funcionamiento del sistema inmune (Xu et al., 2013).

Generalmente la cáscara de naranja es utilizada como alimento para aves y ganado, siendo una fuente potencialmente significativa en el contenido de proteína de origen unicelular, puede ser sometida a un proceso fermentativo, debido a que la cáscara de naranja contiene una cantidad de carbohidratos que la hace atractiva como sustrato (Balu et al., 2012). Se conoce de algunos constituyentes de la cáscara de naranja como pigmentos carotenos, vitaminas y aceites esenciales, así como también celulosa, carbohidratos solubles, pectina, aminoácidos, azúcares y minerales, se encuentran en diferente proporción dependiendo de la capa del tejido de la cáscara (Balu et al., 2012; Xu et al., 2013).

\subsection{Piña}

La piña es una planta natural de los trópicos americanos y pertenece a las familias de las bromelías. La planta de la piña (Ananás- comosus) originaria de Sudáfrica tropical y subtropical, posee interesantes propiedades diuréticas y desintoxicantes, aunque la planta tiene un gran valor ornamental, su fruta es considerada una de las más exquisitas y exóticas que se producen en el mundo. La planta tiene hojas largas lanceoladas, generalmente con espinas en los bordes, estas rosetas de hojas puntiagudas llegan hasta los $90 \mathrm{~cm}$ de longitud que se forman alrededor de un tallo compacto. El fruto nace del ramo floral que se desarrolla en el centro de la planta al final del tallo. Cada piña puede llegar a pesar hasta 4 kilogramos $(\mathrm{kg})$. Las plantas son susceptibles al frío, pero pueden soportar temperaturas hasta de $28^{\circ} \mathrm{F}$ (Escalona et al., 1999).

La piña es originaria de Sudamérica, concretamente de Brasil, allí la encontraron los colonizadores españoles y portugueses. Los indígenas la llamaban Ananas, que significa "fruta excelente" (Edison, 2012). Los valores nutricionales de la piña por 100 gramos de producto comestible, corresponden a $85 \%$ de agua, energía: $49 \mathrm{Kcal}$; proteína: 0,4 g; grasa: 0,4 g; hidratos de carbono: 11,2 g; fibra: 1,2 g; K: 113,0 mg; Mg: 
$14 \mathrm{mg}$; Ca: $13 \mathrm{mg}$; P: $8 \mathrm{mg}$; micros $\mathrm{Fe}, \mathrm{Cu}, \mathrm{Zn}, \mathrm{Mn}$ y Se (trazas); Vitamina A: $2 \mathrm{mg}$; Vitamina C: $2 \mathrm{mg}$; Folato: 10,6 mg (Ácido fólico o vitamina B9) y Vit. E: $0,1 \mathrm{mg}$ (Escalona et al., 1999).

\subsubsection{Generalidades}

La piña es una fruta nativa de Sudamérica, la cual se ha extendido a varios países tropicales. Los principales países productores son Hawái, Filipinas, Taiwán, México, Puerto Rico, entre otros. En términos agronómicos, la piña es una monocotiledónea herbácea, que madura su fruto a los 18 o 22 meses después de plantada. Cada planta produce una sola fruta compuesta sobre su vástago central. Cerca de un año después la planta producirá retoños axilares. Lo que se recomienda es sembrar en suelo de poco drenaje y en lugares con abundante luz solar para tener fruto de buena calidad ya que la temperatura es muy importante para el sabor de la misma (Escalona et al., 1999).

Hasta un $85 \%$ de la piña es agua, con un aporte de calorías equivalente a 55 por cada 100 gramos. Esta fruta ayuda a eliminar o quemar las grasas, siendo muy recomendada y beneficiosa para personas con celulitis, obesidad 0 sobrepeso. La piña tiene propiedades antiinflamatorias, por lo que resulta muy beneficiosa en casos de artritis (Murillo, 2010)

\section{Biodigestores}

Un biodigestor es un recipiente o sistema que mantiene un ambiente biológicamente activo. En algunos casos, es un recipiente en el que se lleva a cabo un proceso químico que involucra organismos o sustancias bioquímicamente activas derivadas de dichos organismos. Un biodigestor anaerobio es una cámara cerrada que impide el ingreso de oxígeno en su interior, en el que se digiere materia orgánica por microorganismos anaerobios, como resultado de este proceso se obtiene biogás utilizable como combustible, generación de electricidad y calefacción; además se produce un efluente rico en nutrientes, el biol, que es ideal como abono orgánico en plantaciones.

Hoy en día se han desarrollado varios tipos de biodigestores que de acuerdo a los arreglos tecnológicos o mejoramiento respecto a la eficiencia, se les han designado diferentes nombres. Los digestores 
convencionales tienen su inicio en la década de los 50, basados en la tecnología aplicada por los franceses y alemanes quienes utilizaron digestores para obtener combustible para los tractores y calefacción para sus viviendas (An et a., 1997). Actualmente existen plantas 0 sistemas de biodigestión de última tecnología o combinaciones de algunos tipos de biodigestores basados principalmente en los más comunes como son el hindú y chino, algunos autores también señalan la importancia del tipo de biodigestor de acuerdo a los procesos de fermentación (Preston \& Rodríguez, 2002).

\subsection{Biodigestión anaeróbica}

La digestión anaeróbica consiste en la descomposición de material biodegradable en ausencia de oxígeno para dar como resultado dos productos principales: biogás (compuesto mayoritariamente por metano) y el lodo estabilizado, conocido como digerido. Esta tecnología utiliza reactores (digestores) cerrados donde se controlan los parámetros para favorecer el proceso de fermentación anaeróbica, un proceso muy conocido, ya que también se produce de un modo natural y espontáneo en diversos ámbitos, como por ejemplo en pantanos, en yacimientos subterráneos o incluso en el estómago de los animales (Garcia-Peña et al., 2011).

La digestión anaerobia es un proceso biológico en el que la materia en ausencia de oxígeno, y mediante la acción bacteriana específica, se descompone en productos gaseosos o "biogás" $\left(\mathrm{CH}_{4}\right.$, $\mathrm{CO}_{2}, \mathrm{H}_{2}, \mathrm{H}_{2} \mathrm{~S}$ ), en un efluente, que es una mezcla de productos minerales (N, P, K, Ca) y compuestos de difícil degradación (Cioabla et al., 2012). El proceso de digestión anaeróbica ocurre por una interacción compleja entre distintos grupos de bacterias. Existen tres grupos de bacterias identificadas que intervienen en cada una de las fases. Las primeras son llamadas bacterias formadoras de ácidos, éstas hidrolizan las moléculas complejas de materia orgánica formando ácidos grasos de cadena corta y alcohol. El segundo grupo está formado por bacterias acetogénicas, que producen acetato e hidrógeno. El tercer grupo llamado metanogénicos, convierte los productos ya degradados a metano y 
dióxido de carbono (Amani et al., 2010).

\section{Conclusiones}

La utilización de nuevas fuentes de energía renovables ha tenido especial interés en los últimos años, puesto que se busca una disminución en el impacto ambiental que se genera por las actividades antropogénicas. Dada la necesidad de aprovechar los residuos de cáscaras de frutas se requieren biorreactores debidamente diseñados y construidos. La investigación promueve la obtención de energías limpias, en aras de maximizar y optimizar el uso de los recursos. El uso de combinaciones de residuos sólidos orgánicos de las frutas en procesos de digestión anaeróbica puede potenciar la producción o rendimiento de metano y a su vez generar mayor productividad y factibilidad desde la perspectiva económica. En este sentido, la piña y naranja pueden ser evaluadas para determinar la relación óptima para obtener mayores rendimientos de producción energética (metano).

Este tipo de tecnologías (digestión anaerobia) da una muestra clara de que nada en el mundo puede considerarse como desecho inutilizable, en concordancia es posible aprovechar muchos subproductos que normalmente son desechados, debido a las bondades de este tipo de proyectos; además, los requerimientos económicos para inversión son relativamente bajos, cuando se comparan con los beneficios obtenidos al usar estas tecnologías.

\section{Bibliografía}

Amani, T., Nosrati, M., \& Sreekrishnan, T. R. (2010). Anaerobic digestion from the viewpoint of microbiological, chemical, and operational aspects-a review. Environmental Reviews, 18(NA), 255-278.

An, B. X., Preston, T. R., \& Dolberg, F. (1997). The introduction of low-cost polyethylene tube biodigesters on small scale farms in Vietnam. Livestock Research for Rural Development, 9(2), 27-35.

Balu, A. M., Budarin, V., Shuttleworth, P. S., Pfaltzgraff, L. A., Waldron, K., Luque, R., \& Clark, J. H. (2012). Valorisation of orange peel residues: waste to biochemicals and nanoporous materials. ChemSusChem, 5(9), 1694-1697.

Cioabla, A. E., Ionel, I., Dumitrel, G. A., \& Popescu, F. (2012). 
Comparative study on factors affecting anaerobic digestion of agricultural vegetal residues. Biotechnology for biofuels, 5(1), 39.

Demirbas, A., \& Ozturk, T. (2005). Anaerobic digestion of agricultural solid residues. International Journal of Green Energy, 1(4), 483-494.

Escalona, M., Lorenzo, J. C., González, B., Daquinta, M., González, J. L., Desjardins, Y., \& Borroto, C. G. (1999). Pineapple (Ananas comosus L. Merr) micropropagation in temporary immersion systems. Plant Cell Reports, 18(9), 743-748.

Garcia-Peña, E. I., Parameswaran, P., Kang, D. W., Canul-Chan, M., \& Krajmalnik-Brown, R. (2011). Anaerobic digestion and co-digestion processes of vegetable and fruit residues: process and microbial ecology. Bioresource Technology, 102(20), 94479455.

Gavilanes-Terán, I., Paredes, C., Pérez-Espinosa, A., Ángeles Bustamante, M., Gálvez-Sola, L., \& Jara-Samaniego, J. (2015). Opportunities and challenges of organic waste management from the agroindustrial sector in South America:

Chimborazo province case Study. Communications in Soil Science and Plant Analysis, 46(sup1), 137-156.
Instituto de Ingeniería. (2012). Disponible en: http://www.smbb.com.mx/revi sta/Revista_2012_2/Revista_ SMBB_2012_V16_n2.pdf.

Murillo, L. O. (2010). Ficha Técnica de industrialización de Piña (Ananas comosus L.). Recuperado el 04 de Septiembre de 2015, de Dirección de Mercadeo y Agroindustria Área Desarrollo de Producto. Disponible en: http://www.cnp.go.cr/bibliotec a/fichas/pina_FTP.pdf

Preston, T. R., \& Rodríguez, L. (2002, March). Low-cost biodigesters as the epicenter of ecological farming systems. In Proceedings biodigester workshop.

Rizk, M. C., Bergamasco, R., \& Tavares, C. R. G. (2007). Anaerobic co-digestion of fruit and vegetable waste and sewage sludge. International Journal of Chemical Reactor Engineering, 5(1).

Saval, S. (2012). Aprovechamiento de residuos agroindustriales: pasado, presente y futuro. BioTecnología, 16(2), 14-46.

Xu, Q., Chen, L. L., Ruan, X., Chen, D., Zhu, A., Chen, C., ... \& Chen, J. (2013). The draft genome of sweet orange (Citrus sinensis). Nature genetics, 45(1), 59.

Zhao, C., Yan, H., Liu, Y., Huang, Y., Zhang, R., Chen, C., \& Liu, G. (2016). Bio-energy conversion 
performance,

biodegradability, and kinetic analysis of different fruit residues during discontinuous anaerobic digestion. Waste management, 52, 295-301. 